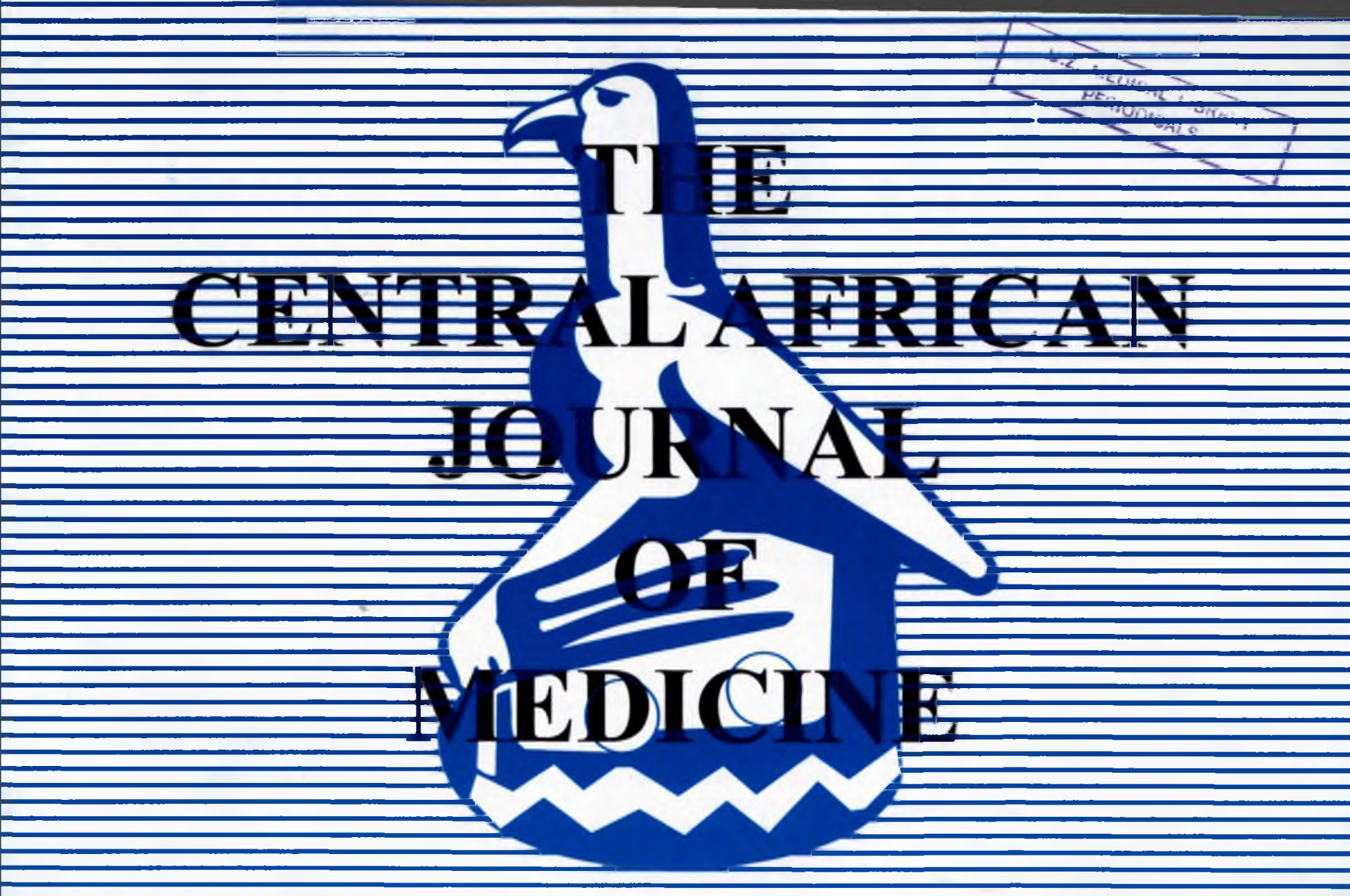

Vol. 55, Nos. 1/4

CONTINTS

JanuarylA rill 2009

ORIGINAL ARTTCLES

HIV status disclosure among people living with

HIV/AIDS at FASO, Mutare, Zimbabwe...

RA Kangwende, J Chirenda, RF Mudyiradima...................1

Incidence of neonatal morbidity at Gondar Town,

Ethiopia.

T Teka, T Desta, A Isheak, S Demamu................................8

Pattern of cleft lip and palate in Dar-es- Salaam...

PMR Caneiro, ER Massawe..

.10

The prices people pay for Medicines in Zimbabwe...

P Gavaza, T Simoyi, B Makunike, CC Maponga...

.14

REVIEW ARTICLE

Medications for chronic pain a practical review...

J Mielke.

NOTES AND NEWS 


\title{
Incidence of neonatal morbidity at Gondar town, Ethiopia
}

\author{
*T TEKA, **T DESTA, *A ISHEAK, *S DEMAMU
}

\begin{abstract}
Objective: To determine the incidence and pattern of neonatal morbidity.

Design: For all neonates delivered in the hospital at least one home visit was arranged to collect morbidity data during neonatal period. This collection took place for a period of one year from 1 September 1995 to 31 August 1996.

Setting: Maternity Ward of the Gondar College of Medical Sciences Hospital.

Patients: 320 neonates were visited at home and were evaluated for any morbidity.

Results: Of the 320 neonates visited at home during the first 24 to 38 days post delivery $83(25.9 \%)$ were found to be sick. URTI (Upper Respiratory Tract Infection), jaundice, pneumonia and neonatal septicimia were diagnosed by physical examination. Non-breastfeeding was associated with neonatal morbidity $(\mathrm{p}<0.001)$.

Conclusions: The neonatal morbidity found during the home visit in this study is very high. A concerted effort is needed to improve both antenatal and post natal care services to prevent neonatal morbidity and to identify sick neonates timely to provide appropriate care in this setting.
\end{abstract}

Cent Afr J Med 2009;55(1/4) 8-10

\section{Introduction}

Perinatal, neonatal and infant mortality rates are now recognized indicators of child health in many countries and regions of the world. To this effect, there are numerous epidemiological and clinical studies that have focused on the causes of perinatal, neonatal and infant mortality in a given community or country. But, information on neonatal morbidity rates are not generally available.' The very limited data on neonatal morbidity also have problems of definition and are not as unambiguous and comprehensive as are the indices of mortality.

Morbidity health interview surveys are widely used in developed countries to obtain information about sickness, disability, and the use of health facilities. An alternative method for collecting morbidity information is a survey based on physical examination where subjects are expected to attend a clinic or to be examined in their dwelling places. Use of clinical medical records also provide information on health as the need arises. Each of these systems of collecting information have their own advantages and disadvantages.

There has been a considerable decrease in neonatal morbidity in developed countries due to improved quality of care by health care providers and especially with the introduction of neonatal intensive care facilities. ${ }^{2,3}$ But, reports from Africa on average still give high figures of morbidity.

* Gondar College of Medical Sciences Hospital

Gondar, Ethiopia

**WHO/AFRO, Zimbabwe
Therefore, a study was undertaken to see the morbidity pattern of neonates born at the Gondar College of Medical Sciences Hospital, over a year. It also attempts to compare the health interview survey with the physical examination finding on neonates who were suspected to be sick.

\section{Materials and Methods}

Home visits were arranged once (during neonatal period) for all neonates delivered at the Gondar College of Medical Sciences (GCMS) during a period of one year from September 1995 to August 1996. In pre-set formats socio-demographic variables; maternal parity; age; height; education and total household income were recorded.

Pertinent history and symptoms were carefully documented and appropriate physical examinations were performed by a general practitioner on all neonates visited. The morbidity data were collected and all were supervised by a paediatrician.

GCMS hospital is a referral and teaching hospital of 350 beds, catering for a population of three million in the Amhara Regional State in the North West part of Ethiopia. The maternity section (Obstetric ward) comprises 20 to 25 beds. There is an operation theatre for elective or emergency surgical obstetric management. The study was approved by the Research and Ethical Committee of the College (GCMS).

\footnotetext{
Correspondence to:

Teshome Desta

Medical Officer for Child and Adolescent Health

WHO/AFRO

Harare, Zimbabwe

Email:destat@zw.afro.who.int/Teshome.desta@yahoo.com
} 


\section{Results}

During the study period, 810 infants were delivered and $74(9.1 \%)$ died immediately after birth. Fifty one neonates $(6.3 \%)$ were found to be sick following delivery and all of them were discharged cured. Table I shows the characteristics of sick and healthy neonates during a single visit at home in the neonatal period.

Table I: Characteristics of sick and healthy neonates born at GCMS 1995 to 1996.

\begin{tabular}{|c|c|c|c|}
\hline Characteristics & $\begin{array}{l}\text { Sick } \\
n=83\end{array}$ & $\begin{array}{l}\text { Healthy } \\
n=237\end{array}$ & p value \\
\hline \multicolumn{4}{|l|}{ Cander: } \\
\hline Male & 43 & 136 & \\
\hline Female & 40 & 101 & 0.38 \\
\hline \multicolumn{4}{|l|}{ Birth weight: } \\
\hline$<1500$ & 1 & 1 & \\
\hline $1500-2499$ & 7 & 11 & \\
\hline $2500-3499$ & 61 & 186 & \\
\hline$>=3500$ & 14 & 39 & 0.66 \\
\hline \multicolumn{4}{|l|}{ Type of feeding } \\
\hline Non Breastfeeding & 32 & 54 & \\
\hline Breeding & 51 & 183 & $<0.001$ \\
\hline
\end{tabular}

Of the 320 neonates visited at home, 83 (25.9\%) neonates were found sick. There was a significant difference in morbidity between breastfed and non breastfed neonates (Chi square test, $p<0.001$ ). Cough, fever and difficulty of feeding were the frequent complaints as perceived by the mother (Figure I). Of the 25 neonates found sick by physical examination, neonatal sepsis, jaundice and pneumonia were the most common clinical diagnosis.

Figure I: Pattern of neonatal morbidity as perceived by the mother.

Figure 1: Pattern of neonatal morbidity as perceived by mother $(n=83)$

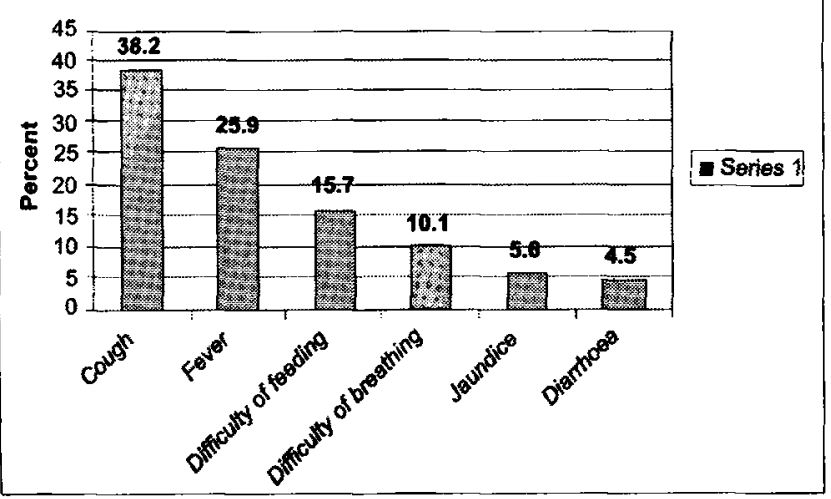

Figure II: Pattern of neonatal morbidity by physical examination.

Figure II: Pattern of neonatal morbidity by physlcal examination $(n=83)$.

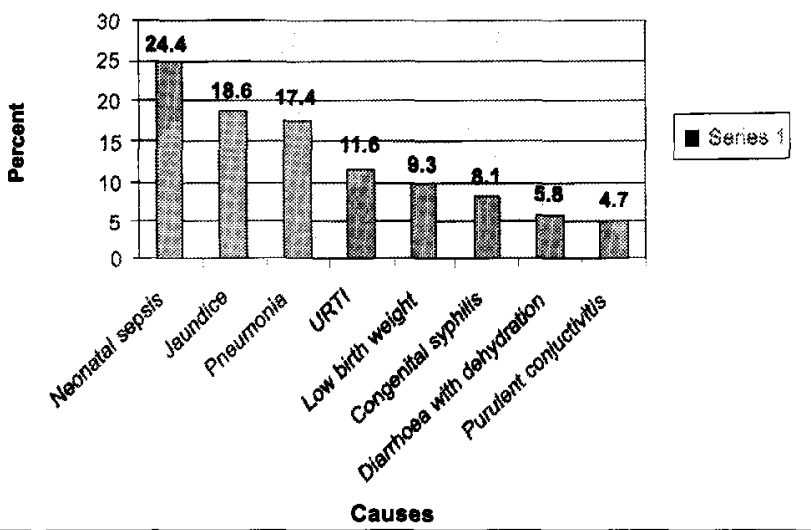

\section{Discussion}

The appropriate allocation of health resources for children in developing countries, requires a knowledge of both mortality and morbidity patterns. Although there are few data on mortality which show a particular event, morbidity data are scarce. The various reasons why medical attention is sought for a child or neonate is not only dependent on objective symptomatology and maternal attitude to illness, but by a number of other factors that vary with location. For example, availability of and access to medical care are important determinants in some countries, while economic factors are primary considerations in others.'

Neonatal morbidity data are generated from surveys, using three methods that include clinical examination, parental recall and use of medical records. In a place where neonatal care is not present, it is difficult to get data from medical records. The parental recall method and use of a self-completed questionnaire or household interviews, used in medical surveys were found to show good correlation between diagnoses obtained by interviews and those reported by attending physician. However, as neonates and infants depend on proxy reports, useful information can be obtained from mothers, whose response are also influenced by many factors. ${ }^{4}$

It is again very difficult to get data on neonatal morbidity as postnatal care services are scanty and are often absent in most African countries. Approximately one-third of women in sub-Saharan Africa give birth in facilities, and no more than $13 \%$ receive a post-natal care visit within two days of delivery. ${ }^{5}$

Neonatal morbidity is known to be dependent on birth weight and gestational age particularly in admitted neonates. But, the pattern of morbidity among neonates after discharge from hospital may seem to be dependent on other factors as well. In the present study there was no difference in healthy and sick neonates in relation to birth weight and gestational age. Introduction of formula milk and cessation of breast 
feeding was associated with neonatal morbidity.

The neonatal morbidity pattern as perceived by the mother indicates respiratory problem as an important feature in this study. This finding is comparable to admitted neonates observed at Ethio-Swedish Children's Clinic ${ }^{6}$ and in other African setting.?

This study revealed that post natal care may only occur if provided through home visits, despite the presence of the health facility nearby. It can be speculated that geographic, financial, and other cultural barriers further limit utilization of post natal care services as the mothers reside far from health facilities. According to a Demographic and Health Survey 2005 (DHS) data in Ethiopia, over $90 \%$ of mothers did not receive any post natal care with in the first six weeks. ${ }^{8}$

It is recommended, therefore, that integrated post natal care services in particular (including home visits) and $\mathrm{MCH}$ services in general through community health extension worker programme and community IMNCI strategy would enhance both the curative and preventive care of newborns. This approach will reduce neonatal morbidity by providing basic neonatal preventive home care and counseling on breast feeding, and on early identification of general danger signs in the newborn which would ultimately improve neonatal health and save lives. No country can afford not to address neonatal health. It is not possible to achieve the Millennium Development Goal 4 without addressing neonatal survival since neonatal deaths account for a high proportion of deaths among children under the age of five years; up to $38 \%$ globally and 24 to $56 \%$ at regional level. ${ }^{9,10}$

\section{Acknowledgements}

The Ethiopian Science and Technology Commission (ESTC) funded this study project. The authors extend their gratitude to the Commission and the Health Department atESTC.

\section{References}

1. Baum JD, Birth Risks, ed. Nestle Nutrition Workshop Series, Vol. 31. Nestle Ltd. (New York:Vevey/Raven Press 1993).

2. Lee KS, Pameth N, Garner LM. Neonatal mortality. An analysis of recent improvement in the United States. Am J Public Health 1980:70:15.

3. Koops BL, Morgan LJ, Battaglia FC. Neonatal mortality risk in relation to birth weight and gestational age: Update. J Paediat 1982;101:969.

4. Mechanic D. The influence of mothers in their children's health attitudes and behavior. Pediatrics 1964;33:444-53.

5. Charlotte Warren et al. "Postnatal Care." In: Opportunities for Africa's newborns, Ed. J Lawn, K Kerber. (Cape Town, South Africa: Partnership for Maternal, Newborn, and Child Health, Save the Children, UNFPA, UNICEF, USAID, WHO, and partners, 2006).

6. Tafari N, Manshande M. Neonatal morbidity in Addis Ababa, Ethiopia. Ethiop Med $J$ 1978;16:139.

7. Kadirye-Banda E, Musoke FN. Neonatal morbidity and mortality at Kenyatta National Hospital newborn unit. East Afr Med $J$ 1992;69:360-5.

8. Ethiopia Demographic and Health Survey 2005. Central Statistical Agency, Addis Ababa, Ethiopia and ORC Macro, Calverton, Maryland, USA 2006.

9. Joy E. Lawn et al. 4 million neonatal deaths: When? Where? Why? Lancet 2005;365:891900.

10. Jose Martines et al. Neonatal survival: a call for action. Lancet 2005;1-9. 


\section{(c) (1) (9)}

This work is licensed under a

Creative Commons

Attribution - NonCommercial - NoDerivs 3.0 License.

To view a copy of the license please see:

http://creativecommons.ora/licenses/bv-nc-nd/3.0/ 